\title{
Japanese language learners' perceptions of strategies use and their effectiveness in kanji learning
}

\author{
To Quoc Minh Huan ${ }^{1 *}$ \\ ${ }^{1}$ Ho Chi Minh City Open University, Vietnam \\ *Corresponding author: huan.tqm@ou.edu.vn
}

\begin{tabular}{ll}
\hline \multicolumn{1}{c}{ ARTICLE INFO } & \multicolumn{1}{c}{ ABSTRACT } \\
\hline $\begin{array}{l}\text { DOI:10.46223/HCMCOUJS. } \\
\text { soci.en.9.2.262.2019 }\end{array}$ & $\begin{array}{l}\text { Kanji learning is considered to be a hard job when it } \\
\text { comes to learning Japanese. However, studies on kanji } \\
\text { learning strategies are uncommon in Japanese language } \\
\text { academia in Vietnam. In other countries, many research }\end{array}$ \\
Received: November 6 ${ }^{\text {th }}, 2019$ & $\begin{array}{l}\text { models on kanji learning strategy use and effectiveness were } \\
\text { developed. With regard to language context in Vietnam, this } \\
\text { Revised: December } 6^{\text {th }}, 2019\end{array}$ \\
Accepted: December 13 ${ }^{\text {th }}, 2019$ & $\begin{array}{l}\text { paper reports an investigation on the relationship between } \\
\text { strategy use and effectiveness, and learners perceived } \\
\text { effectiveness of kanji learning strategy. Data collected from } \\
\text { 122 learners has given some solid answers to the questions on } \\
\text { strategy use - effectiveness relationship and perceived } \\
\text { effectiveness of learners. }\end{array}$ \\
Keywords: &
\end{tabular}

\section{Introduction}

Learning kanji characters and words are one of the most challenging matters for L2 Japanese learners. Kanji or Chinese characters are parts of a complex logographic writing system using in both Japan and China (Grainger, 2005; Verdonschot, 2011). There are 2,136 Jouyou kanji or regular use kanji issued by the Japan Agency for Cultural Affairs (2012), which have been specified for daily life in Japan. To learn those regular kanji, L2 Japanese students have to obtain a great amount of knowledge of kanji. Knowledge of kanji may consist of meaning, sound, strokes, orthography features, morphological structure, collocations (Mori, 2014). Hence, Gamage (2003) suggested that research on kanji learning strategies should be conducted separately from vocabulary learning research.

Oxford (1990) suggested a self-reported assessment tool named Strategy Inventory for Language Learning (SILL), including six subgroups of memory, cognitive, compensation, social, affective and metacognitive. Bourke (1997) introduced Strategy Inventory for Learning Kanji (SILK) as a tool for identifying strategies in use for learning kanji. SILK grouped specific characteristics-based techniques of kanji learning into direct and indirect groups. Ever since many researchers have developed customized versions of SILL and SILK and regrouped kanji learning strategies into different groups in regard to research purposes. Many researchers on learners' perception, attitude, and effectiveness of kanji learning strategies have divided learning strategies into groups which can be listed as rote-memorization, morphological analysis, context-based strategies, association methods or mnemonics, metacognitive. 
(Gamage, 2003; Kubota \& Toyoda, 2001; Mori, 2003; Mori \& Nagy, 1999; Mori, Sato, \& Shimizu, 2007; Rose, 2017; Shimizu \& Green, 2002). In addition, Mori et al. (2007) stated that helplessness as elements contrasted with metacognitive can help learners in finding efficient kanji learning strategies.

In Vietnam, Than (2005) reported that repeated writing is the most popular technique among learners. Research showed that there are differences in strategies choosing among learners at different levels in universities. However, the major limitation was the lack of investigation on the efficiency of kanji learning strategies.

In terms of improving learners' learning process, this paper is a preliminary effort to find out differences in perceived kanji learning strategies by learners at various proficiency levels. Also, this investigation attempts to clarify the frequency of learning strategies among learners and their perceptions of the efficiency of learning strategies, which have not been explored in the previous studies in Vietnam.

\section{Literature review}

\subsection{Kanji learning strategy classification}

In terms of kanji learning strategy classifications, Oxford (1990) believed that learning strategies could be divided into two major classes as direct strategies referring to the subconscious task and indirect strategies referring to cognitive strategies. The two-class system was split into six groups of memory, cognitive, compensation, social, affective and metacognitive. O'Malley and Chamot (1990), in contrast, categorized into cognitive, metacognitive and social/affective. Cognitive strategies are considered as learning techniques and steps that learners need to take to transform new language material. Metacognitive strategies described as coordinating one's own efforts to learning tasks. Social/affections strategies involve taking control of learners' feelings about language learning. Bourke (1997) introduced SILK, a specific characteristic-based assessment tool for learners on kanji learning strategies. Like Oxford' SILL, SILK's learning strategies can be divided into direct (for learners to handle learning tasks) and indirect (for learners to manage kanji learning) strategy groups. Items in SILK can be classified into 15 topics related to the processing of kanji learning. Each topic or strategy is given with descriptions to help learners better understand the learning strategies. Based on those approaches, later research of Mori and Shimizu (2007) concluded that there are six self-reported kanji learning strategies: morphological analysis, rote memorization, context-based strategies, association method, metacognitive strategies, and helplessness.

Rote memorization includes repeated writing (Naka, 1998; Naka \& Naoi, 1995), tracking, copying (Onose, 1987, 1988) and learning of formulaic chunks (Myles, Hooper, \& Mitchell, 1998). Rote memorization strategies help learner at the beginner level succeed in dealing with their first attempts at learning kanji (Nesbitt, 2009), a writing system with multiple aspects, including meaning(s), sound(s), stroke order, orthography feature, collocations (Mori, 2014). Nesbitt (2009) reported that rote-learning methods can create and reinforce neural pathways to procedural memory, a memory system that involves an automatic execution of habit or unconscious learning. Notwithstanding having many learning strategies, learners still depend on rote learning skills for target kanji (Gamage, 2003). 
In spite of having pictographs and ideograph, the most common character's structure can be found in kanji or Chinese characters is a semantic-phonetic compound (Verdonschot, 2011). The semantic-phonetic compound is constructed of two parts: semantic radical and phonetic component. The semantic radical will contribute to the meaning and the phonetic component will contribute to the approximate pronunciation (Feldman \& Siok, 1999; Shu \& Anderson, 1995). Kanji morphological or component analysis is a learning strategy that learners break down the internal structure of a kanji character which is constructed by semantic radical and phonetic components. L2 Japanese students can recognize familiar components of a new kanji character or word by giving a demonstration of the ability to use built-in kanji knowledge of semantic radicals, phonetic components and their functions (Kondo-Brown, 2006; Kubota \& Toyoda, 2001; Mori, 2003; Mori et al., 2007; Rose, 2017; Yamashita \& Maru, 2000).

Context-based strategies are learning with contextual information compared with learning words in isolation (Mori, 2014; Mori et al., 2007). L2 students' use of context-based strategies to learn novel words have been particularly supported by evidence (Brown, Sagers, \& LaPorte, 1999; Day, Omura, \& Hiramatsu, 1992; Fraser, 1999; Huckin \& Bloch, 1993; Li, 1988). Context provides students with broad information that help learners find out the word class of the kanji word in a given context (Mori, 2003). It is significantly giving good effects when combined context-based strategies and morphological strategies (Mori, 2002, 2003).

Association methods or mnemonics are types of memory-enhancing learning methods. Learners would use their personal technique or mental image to encode kanji characters or words (Kuo \& Hooper, 2004). Those personal techniques or metal images are familiar elements such as visual image (Wang \& Thomas, 1992), keywords (Thomas \& Wang, 1996; Wang, Thomas, \& Ouellette, 1992), and phonological alike to target kanji (Mori, 2014). Aids from memory can support learners with common establishments or peculiar self - generating (Kuo \& Hooper, 2004; Thomas \& Wang, 1996). When a meaningful association is made, association methods can stimulate the meaning and the reading of the kanji. These methods are quite useful for L2 Japanese learners (Rose, 2013).

Metacognitive strategies are used to earn awareness of one's own learning process (O’Malley \& Chamot, 1990; Oxford, 1990). Knowledge of cognition, learners' understanding of cognitive resources, and cognition regulation or carrying out resource control are components of metacognitive knowledge (Bialystok \& Ryan, 1985; Flavell, 1978). Metacognitive strategies consist of understandings of a given task, kanji learning strategy selection. Furthermore, the stage of one's own learning coordination, the progress of monitoring, and the self-directed development of kanji knowledge are of the most important stages of Kanji learning metacognitive strategies (Mori, 2012, 2014). In contrast with metacognitive methods, helplessness, which was identified as a disjunct factor of strategy (Mori et al., 2007), is the feeling when students who have felt lost without knowing effective kanji learning strategies benefit from metacognitive instruction that familiarizes them with various learning strategies (Mori, 2012).

\subsection{Previous studies related to the topic}

Gamage (2003) conducted research on 116 second-year undergraduate students in Australia. This research, based on Bourke's SILK, found that rote writing is the most popular and efficient strategies of kanji learning among alphabet background participants. Furthermore, this research reported that alphabetic background learners rely on visual strategies and character background learners rely on phonological strategies. 
In research of Shen (2005), orthographic-knowledge-based strategies are the most frequently used. As mention in this research, orthographic-knowledge-based strategies are strategies that use the knowledge of Chinese characters includes radicals, phonetics, semantics, stroke orders to learn the target kanji. This approach is similar to the morphological analysis strategy definition.

Kanji learning strategy research of Mori and Shimizu (2007) showed that rote memorization is the most effective and frequently used strategy among students. This research was conducted on 311 subjects mostly university students with 245 of them at the pre-advanced and intermediate level. Sung (2014) reported that out of 10 most used strategies were 3 rote memorizations, 4 association strategies, 1 morphological analysis, 1context-based, 1 metacognitive. This research was conducted on 88 participants in the USA.

In Vietnam, Than (2005) reported that repeated writing, dictionary looking up and learning from errors are the most popular technique among learners. Research suggests that first-year students rely on association methods, second-year students rely on association methods, context-based methods and metacognitive methods. In addition, third-year students tend to choose morphological methods. Then assumed that there is a relationship between strategy use and effectiveness.

Research questions:

1. What is the relationship between the frequency of strategies use and effectiveness?

2. What is the difference between learners at the elementary level and higher proficiency levels on perceived learning strategies' effectiveness?

\section{Questionnaire}

The questionnaire was adapted from Bourke's SILK (1997). To record the frequency of kanji learning strategies, the questionnaire items were designed based on Bourke's Strategy Inventory for Learning Kanji and its Likert scale. Other studies that affected the questionnaire were those of Shimizu and Green (2002), Gamage (2003), and Mori and Shimizu (2007).

The questionnaire included 2 parts. Part one was for background information gathering. In this part, participants provided information such as Japanese language proficiency level, occupation, and age. Part two consisted of 14 statements of using kanji learning strategies adopted from the work of Bourke (1997) and Gamage (2003). The statements described the use of particular kanji learning strategies with simple and familiar words to those who are Japanese language learners as in a study of Than (2005). After reading the statements, participants were asked to rate the frequency of strategies use and perceived effectiveness of the described kanji learning strategies. Statements were grouped similar to those in Mori's work (2007). Those groups were morphological analysis (2 statements, B1 and B2), associations methods (4 statements, C1, C2, C3 and C3), context-based strategies (2 statements, D1 and D2), rote memorization (3 statements, E1, E2 and E3), and metacognitive strategies (3 statements, F1, F2 and F3). Responses were assigned a score based on a 5-point Likert scale with frequency rate "1" being "Never", "2" being "Almost Never", "3" being "Sometimes", "4" being "Quite Often" and "5" being "Very Often". In terms of effectiveness rating, "1", "2", "3", "4" and "5" correspond with "Helpless", "Almost Helpless", "Neither helpless nor helpful" "Helpful" and "Very Helpful". 


\section{Participants}

Participant demographic background information was collected through the first part of the questionnaire. Among 122 participants, 65 participants $(53,3 \%)$ were at an elementary proficiency level while 52 participants $(42,6 \%)$ were at an intermediate proficiency level. Also, 2 participants $(1,6 \%)$ were at the pre-advance proficiency level and $1(0,8 \%)$ was at the advanced level. 66 participants $(54,1 \%)$ were first-year, second-year students. 41 participants $(33,6 \%)$ were third-year, fourth-year students. 8 participants $(6,6 \%)$ were Japanese language teachers. Most of the participants were Japanese language or Japanese studies major $(n=100$, $82 \%)$.

\section{Result and discussions}

\subsection{Relationship between strategies use and effectiveness}

To investigate the relationship between strategies use and effectiveness, this paper compares mean responses of each statement. Mean of each response was measured and illustrated in Figure 1.

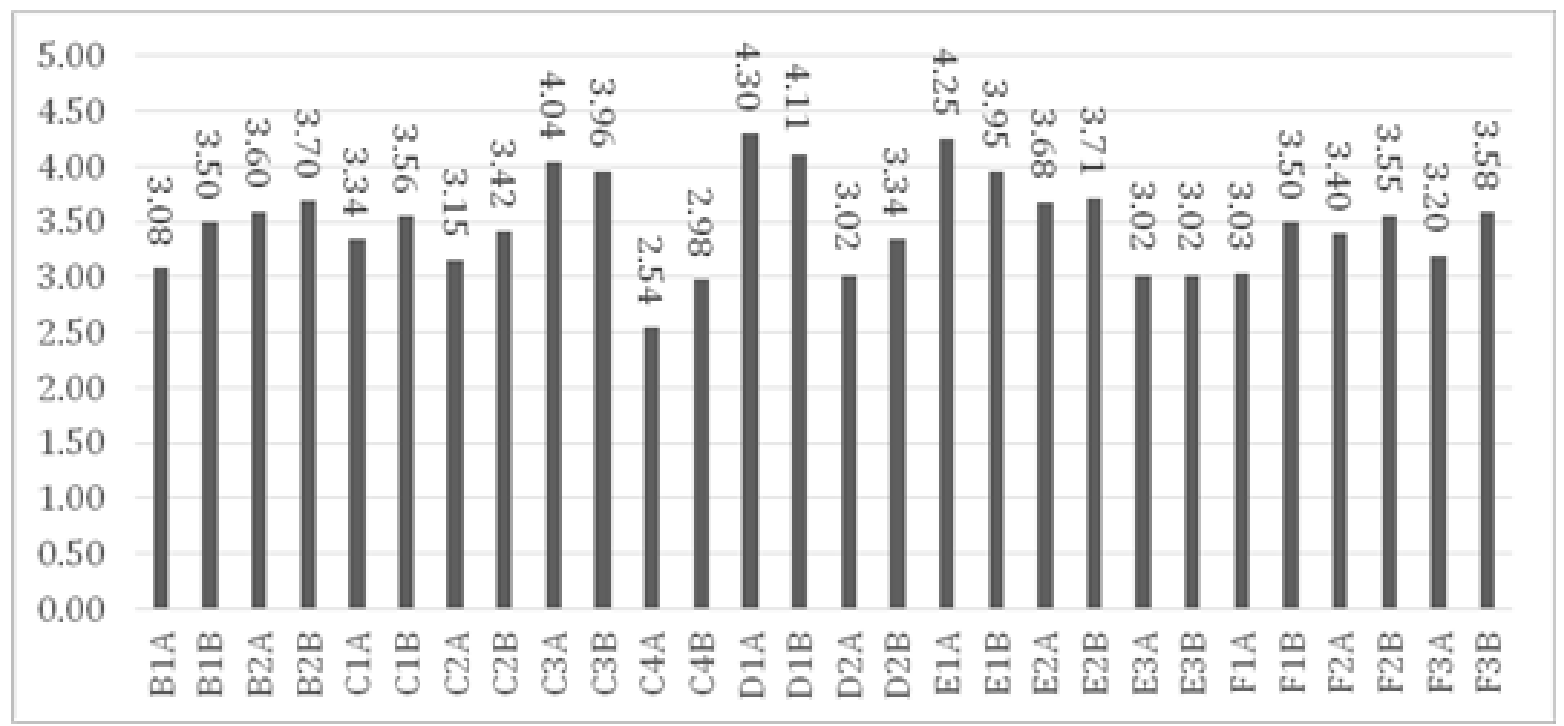

Figure 1. Kanji learning strategies using frequency and perceived effectiveness

In Figure 1, the x-axis shows 14 kanji learning strategy statements divided into 5 groups (morphological analysis, association methods, context-based methods, memorization, and metacognitive strategies). The A-endings mean participants' rating on the frequency and the Bendings mean rating on effectiveness. The y-axis indicates the average response (column) of subjects. The higher each bar is, the more participants declared that they use kanji learning strategy often or think that strategy helpful.

Figure 1 shows that in most cases the average efficiency of learning strategies is higher than the average of usage. In the cases of C3, D1, and E1 strategies use frequency ratings are slightly higher than average effectiveness $(0,08,0,19$ and 0,30). A context-based strategy, an association strategy, and two rote memorization methods are the most use kanji learning strategies. "I put new kanji in words that the kanji appears" (D1A, mean=4,30) is the most use 
strategy. Rote memorization methods seem to be quite popular methods among learners with two high rating statements, "I writing kanji by writing them out numerous times" (E1A, mean=4,25) and "I pronounce new kanji repeatedly" (E2A, mean=3,68). An association strategy that appeared to be frequently used is using Sino-Vietnamese pronunciation as a way to remember kanji $(\mathrm{C} 3 \mathrm{~A}$, mean=4,04). One morphological analysis strategy that appears on the top 5 five is analyzing kanji strokes order and radicals $(\mathrm{B} 2 \mathrm{~A}$, mean=3,60).

From the results, it is clear that the most frequently used strategies came from various types of learning strategies. A similar pattern of results was obtained in works of Gamage (2003), Than (2005), Mori and Shimizu (2007) and Sung (2014). In line with previous studies, rote memorization appears to be one of the most frequently used strategies. As reported by Than (2005), the evidence point out that Sino-Vietnamese pronunciation association methods are also popular among Vietnamese learners. However, a morphological analysis strategy and an association strategy appeared to be one of the most used strategies. This result shares similarities with Shen (2005) and Sung (2014).

\section{Table 1}

Pearson correlation between strategies use responses and perceived effectiveness responses on the same statements

\begin{tabular}{cccccccc}
\hline Statements & B1 & B2 & C1 & C2 & C3 & C4 & D1 \\
\hline $\begin{array}{c}\text { Pearson } \\
\text { Correlation }\end{array}$ & 0,627 & 0,759 & 0,804 & 0,848 & 0,745 & 0,766 & 0,746 \\
\hline Statements & D2 & E1 & $\mathbf{E 2}$ & $\mathbf{E 3}$ & $\mathbf{F 1}$ & $\mathbf{F 2}$ & $\mathbf{F 3}$ \\
\hline $\begin{array}{c}\text { Pearson } \\
\text { Correlation }\end{array}$ & 0,789 & 0,682 & 0,768 & 0,835 & 0,646 & 0,875 & 0,651 \\
\hline
\end{tabular}

Note: $\mathrm{N}=122, \mathrm{p}<0,01,2$-tailed

Source: The researcher's data analysis

A bivariate Pearson correlation was run to evaluate the relationship between strategies use frequency and effectiveness. Table 1 shows that the highest correlation coefficient of strategies is 0,875 , and the lowest correlation coefficient is 0,627 . Correlation coefficients indicated strong relationships. In addition, $\mathrm{p}<0.001$ indicated coefficient is significantly different from 0 . Hence, there is evidence that strategies use frequency is related to effectiveness. Specifically, it seems that the more effective strategies are, the higher frequency of strategy use. These result correlates fairly well with Gamage (2003) and further supports the idea of a strong relationship between strategy use and strategy effectiveness. In the language context of Vietnam, Than (2005) only presumed the relationship between strategies use and effectiveness without any statistical evidence.

\subsection{Perceived effectiveness}

In order to answer the second question, an independent-samples t-test was conducted. The first t-test was run to compare perceived effectiveness between learners at higher proficiency levels (intermediate, pre-advanced and advanced; Group 1) and learners at elementary proficiency level (Group 2). 


\section{Table 2}

T-test with significant differences on strategy effectiveness

\begin{tabular}{cccccccccccc}
\hline & \multicolumn{3}{c}{ Proficiency level } & \multicolumn{1}{c}{ 95\% CI } \\
& \multicolumn{3}{c}{ Group 1 } & & & Group 2 & of the & t & df & p \\
& M & SD & $\mathbf{n}$ & M & SD & $\mathbf{n}$ & Difference & & & \\
\hline C2B & 3,73 & 1,13 & 55 & 3,22 & 1,097 & 65 & $0,108-0,915$ & 2,513 & 118 & 0,013 \\
\hline C3B & 4,16 & 0,856 & 55 & 3,82 & 0,846 & 65 & $0,040-0,657$ & 2,236 & 118 & 0,027 \\
\hline D1B & 4,27 & 0,757 & 55 & 3,94 & 0,998 & 65 & $0,009-0,659$ & 2,037 & 118 & 0,044 \\
\hline F1B & 3,78 & 0,917 & 55 & 3,31 & 0,917 & 65 & $0,141-0,807$ & 2,827 & 118 & 0,006 \\
\hline
\end{tabular}

Note: $\mathrm{N}=122, \mathrm{p}<0,01,2$-tailed

Source: The researcher's data analysis

Table 2 show that there are 4 items with significant differences between the two groups. Significant differences were founded on the perceived effectiveness on strategies such as comparing kanji meaning and pronunciation, using Sino-Vietnamese pronunciation, putting kanji characters in words and planning for kanji learning. Specifically, higher proficiency level learners perceived some association strategies, context-based strategies and metacognitive strategies more helpful than ones at lower level. A work of Shen (2005) suggested similar results. On account of deeper orthographic knowledge, learners at higher proficiency level seemed to rely more on orthographic knowledge-based strategies (Shen, 2005). Those strategies fit to our classification as morphological and association methods. Furthermore, Shen (2005) stated that when achieving advanced level, learners are more aware of the helpfulness of metacognitive strategies.

\section{Conclusions}

This study suggests that the most used learning strategies are also the most effective strategies. In some cases, in spite of lower use frequency, perceived effectiveness is higher. This means even not using those strategies often, learners are still aware of the effectiveness of strategies. Mori and Shimizu (2007) found that attitude toward kanji related to strategy choice and the perceived effectiveness of kanji learning strategies. Additionally, participants at different proficiency levels have differences in awareness of helpfulness of kanji learning strategies. Learners at higher levels find that some kanji-knowledge-based strategies and metacognitive strategies more helpful than ones at lower levels. The differences might be created by differences in knowledge of orthographic or learning experiences (Shen, 2005). Further studies should discover factors that affect strategy choice and perceived effectiveness such as elements from textbooks or teachers' kanji learning strategy instruction.

There are some limitations that should be noted. Firstly, previous studies have different classifications for kanji learning strategies. Some researchers prefer to sort learning strategies based on orthographic characteristics (Gamage, 2003). Other researchers divide strategies into groups with similar features (Mori \& Shimizu, 2007; Shen, 2005). Some studies just introduce 
strategies or techniques without any classification (Sung, 2014; Than, 2005). These differences in classification make it difficult to compare the findings of those studies. Secondly, there are limitations to resource access. Literature review might not cover many studies from other countries with different language contexts. Lastly, kanji acquisitions and learning strategies might not be a popular topic among researchers. Hence, making comparisons with studies in Vietnam is quite a difficult matter.

\section{References}

Academy of Managers for Construction and Cities. (2018). Tầm nhìn đô thị thông minh tại Việt Nam [Smart urban's vision in Vietnam]. Retrieved March 25, 2019, from http://amc.edu.vn/vi/tin-tuc-su-kien/tin-xay-dung-va-do-thi/khoa-hoc-cong-nghe-moitruong/7136-tam-nhin-do-thi-thong-minh-tai-viet-nam.html

Agency for Cultural Affairs. (2012). Jōyō Kanji table (2010 Cabinet notification no. 2). Retrieved March 20, 2019, from http://www.bunka.go.jp/kokugo_nihongo/sisaku/joho/joho/kijun/naikaku/kanji/

Bialystok, E., \& Ryan, E. B. (1985). A metacognitive framework for the development of first and second language skills. Metacognition, Cognition, and Human Performance, 1, 207252.

Bourke, B. (1997). Maximising efficiency in the kanji learning task (Doctoral dissertation, University of Queensland, Brisbane, Australia).

Brown, C., Sagers, S. L., \& LaPorte, C. (1999). Incidental vocabulary acquisition from oral and written dialogue journals. Studies in Second Language Acquisition, 21(2), 259-283.

Day, R. R., Omura, C., \& Hiramatsu, M. (1992). Incidental EFL vocabulary learning and reading. Reading in a Foreign Language, 7, 541-541.

Feldman, L. B., \& Siok, W. W. T. (1999). Semantic radicals contribute to the visual identification of Chinese characters. Journal of Memory and Language, 40(4), 559-576.

Flavell, J. H. (1978). Metacognitive development. In M. N. Scandura \& C. J. Brainerd (Eds.), Structural/process theories of complex human behavior (pp. 213-245). Netherlands: Sijthoff and Noordhoff.

Fraser, C. A. (1999). Lexical processing strategy use and vocabulary learning through reading. Studies in Second Language Acquisition, 21(2), 225-241.

Gamage, G. (2003). Issues in strategy classifications in language learning: A framework for kanji learning strategy research. Retrieved March 25, 2019, from https://ro.uow.edu.au/cgi/viewcontent.cgi?article=1069\&context=artspapers

Gamage, G. (2003). Perceptions of kanji learning kanji strategies: Do they differ among Chinese character and alphabetic background learners? Australian Review of Applied Linguistics, 26(2), 13-14.

Grainger, P. (2005). Second language learning strategies and Japanese: Does orthography make a difference? System, 33(2), 327-339. 
Huckin, T., \& Bloch, J. (1993). Strategies for inferring word-meanings in context: A cognitive model. In Second language reading and vocabulary learning (pp. 153-178).

Kondo-Brown, K. (2006). How do English L1 learners of advanced Japanese infer unknown kanji words in authentic texts? Language Learning, 56(1), 109-153.

Kubota, M., \& Toyoda, E. (2001). Learning strategies employed for learning words written in kanji versus kana. Australian Review of Applied Linguistics, 24(2), 1-16.

Kuo, M.-L. A., \& Hooper, S. (2004). The effects of visual and verbal coding mnemonics on learning Chinese characters in computer-based instruction. Educational Technology Research and Development, 52(3), 23-34.

$\mathrm{Li}, \mathrm{X}$. (1988). Effects of contextual cues on inferring and remembering meanings of new words. Applied Linguistics, 9(4), 402-413.

Mori, Y. (2002). Individual differences in the integration of information from context and word parts in interpreting unknown Kanji words. Applied Psycholinguistics, 23, 375-397. doi:10.1017.S0142716402003041

Mori, Y. (2003). The roles of context and word morphology in learning new kanji words. The Modern Language Journal, 87(3), 404-420.

Mori, Y. (2007). Expressive Japanese: A reference guide to sharing emotion and empathy. The Modern Language Journal, 91(1), 140-141.

Mori, Y. (2012). Five myths about "Kanji" and "Kanji" learning. Japanese Language and Literature, 46(1), 143-169.

Mori, Y. (2014). Review of recent research on kanji processing, learning, and instruction. Japanese Language and Literature, 48(2), 403-430.

Mori, Y., \& Nagy, W. (1999). Integration of information from context and word elements in interpreting novel kanji compounds. Reading Research Quarterly, 34(1), 80-101.

Mori, Y., Sato, K., \& Shimizu, H. (2007). Japanese language students' perceptions on Kanji learning and their relationship to novel Kanji word learning ability. Language Learning, 57(1), 57-85.

Mori, Y., \& Shimizu, H. (2007). Japanese language students' attitudes toward kanji and their perceptions on kanji learning strategies. Foreign Language Annals, 40(3), 472-490.

Myles, F., Hooper, J., \& Mitchell, R. (1998). Rote or rule? Exploring the role of formulaic language in classroom foreign language learning. Language Learning, 48(3), 323-364.

Naka, M. (1998). Repeated writing facilitates children's memory for pseudocharacters and foreign letters. Memory \& Cognition, 26(4), 804-809.

Naka, M., \& Naoi, H. (1995). The effect of repeated writing on memory. Memory \& Cognition, 23(2), 201-212.

Nesbitt, D. (2009). Achieving unconscious recall of Kanji: Can rote learning help? New Zealand Studies in Applied Linguistics, 15(2), 61-73.

O’Malley, M. J., \& Chamot, A. U. (1990). Learning strategies in second language acquisition. Cambridge, UK: Cambridge University Press.

Onose, M. (1987). The effect of tracing and copying practice on handwriting skills of Japanese 
letters in preschool and first grade children. Japanese Journal of Educational Psychology, 35(1), 9-16.

Onose, M. (1988). Effect of the combination of tracing and copying practices on handwriting skills of Japanese letters in preschool and first grade children. Japanese Journal of Educational Psychology, 36, 129-134.

Oxford, R. (1990). Language learning strategies. New York, NY: Newbury House Publishers.

Oxford, R. (1990). Language learning strategies: What every teacher should know. Boston, MA: Heinle \& Heinle.

Rose, H. (2013). L2 learners' attitudes toward, and use of, mnemonic strategies when learning Japanese kanji. The Modern Language Journal, 97(4), 981-992.

Rose, H. (2017). The Japanese writing system: Challenges, strategies and self-regulation for learning kanji. Bristol, UK: Multilingual Matters.

Shen, H. H. (2005). An investigation of Chinese-character learning strategies among non-native speakers of Chinese. System, 33(1), 49-68.

Shimizu, H., \& Green, K. E. (2002). Japanese language educators' strategies for and attitudes toward teaching kanji. The Modern Language Journal, 86(2), 227-241.

Shu, H., \& Anderson, R. C. (1995). Role of radical awareness in the character and word acquisition of Chinese children. Champaign, IL: University of Illinois at UrbanaChampaign.

Sung, K.-Y. (2014). Novice learners' Chinese-character learning strategies and performance. Electronic Journal of Foreign Language Teaching, 11(1), 38-51.

Than, T. K. T. (2005). Phương pháp học chữ Hán của người Việt Nam học tiếng Nhật [Japanese Kanji learning strategies of Vietnamese learners]. Kỷ yếu Hội thảo ngành Thông tin-Thu viện (LIC), 513-522.

Thomas, M. H., \& Wang, A. Y. (1996). Learning by the keyword mnemonic: Looking for longterm benefits. Journal of Experimental Psychology: Applied, 2(4), 330-342.

Verdonschot, R. (2011). Word processing in languages using non-alphabetic scripts: The cases of Japanese and Chinese. Utrecht, Netherlands: LOT.

Wang, A. Y., \& Thomas, M. H. (1992). The effect of imagery-based mnemonics on the long term retention of Chinese characters. Language Learning, 42(3), 359-376.

Wang, A. Y., Thomas, M. H., \& Ouellette, J. A. (1992). Keyword mnemonic and retention of second-language vocabulary words. Journal of Educational Psychology, 84(4), 520-528.

Yamashita, H., \& Maru, Y. (2000). Compositional features of kanji for effective instruction. The Journal of the Association of Teachers of Japanese, 34(2), 159-178. 